\title{
MAGNETO-POLAR FLUID FLOW THROUGH A POROUS MEDIUM OF VARIABLE PERMEABILITY IN SLIP FLOW REGIME
}

\author{
P.K. GAUR, A.K. JHA* and R. SHARMA \\ Department of Mathematics, JECRC University \\ Jaipur, Rajasthan, 303905, INDIA \\ E-mails: pradeep.gaur@jecrcu.edu.in; itsabhay@rediffmail.com
}

\begin{abstract}
A theoretical study is carried out to obtain an analytical solution of free convective heat transfer for the flow of a polar fluid through a porous medium with variable permeability bounded by a semi-infinite vertical plate in a slip flow regime. A uniform magnetic field acts perpendicular to the porous surface. The free stream velocity follows an exponentially decreasing small perturbation law. Using the approximate method the expressions for the velocity, microrotation, and temperature are obtained. Further, the results of the skin friction coefficient, the couple stress coefficient and the rate of heat transfer at the wall are presented with various values of fluid properties and flow conditions.
\end{abstract}

Key words: polar fluid, MHD, permeability, slip-flow, heat transfer.

\section{Introduction}

The fluids which sustain couple stresses, called polar fluids, contain micro-structures which are mechanically significant when the characteristic dimension of the problem is of the same order of magnitude as the size of the micro-structure. Extensive reviews of the theory can be found in the review article by Cowin [1]. Since the micro-structure size is the same as the average pore size, it is relevant to study the flow of polar fluids through a porous medium. The examples of fluids which can be modeled as polar fluids are slurries, polymer additives, etc. The effects of couple stresses on the flow through a porous medium were investigated by Raptis [2], Patil and Hiremath [3-4] analyzed the free convection effects on the oscillatory flow of couple stress fluids through a porous medium. Sharma and Gupta [5] examined the effects of thermal convection in micropolar fluids through porous medium. The effect of rotation on thermal convection in micropolar fluids through a porous medium was studied by Sharma and Kumar [6], Raptis and Takhar [7] examined a steady flow of a polar fluid through a porous medium by using the generalized Forchheimer's model. Kim [8] investigated the unsteady free convection flow of a micropolar fluid past a vertical plate embedded in a porous medium. Hassanein et al. [9] examined the effects of natural convection flow of a micropolar fluid from a permeable uniform heat flux surface in a porous medium. Sharma and Sharma [10] studied the couple stress fluid permeated with suspended particles heated and soluted from below in a porous medium. The study of flow and heat transfer for an electrically conducting polar fluid past a porous plate under the influence of a magnetic field has attracted the interest of many investigators in view of its applications in many engineering problems, such as magnetohydrodynamic (MHD) generators, plasma studies, nuclear reactors, oil explorations, geothermal energy extractions and the boundary layer control in the field of aerodynamics. Also, the porous media heat transfer problems have several practical engineering applications, such as the crude oil extraction, the ground water pollution, and many other practical applications, i.e., in biomechanical problems (e.g., blood, flow in the pulmonary alveolar sheet) and in the filtration transpiration cooling. The unsteady hydromagnetic free convection flow of a Newtonian and polar

\footnotetext{
* To whom correspondence should be addressed
} 
fluid was investigated by Helmy [11]. El-Hakien et al. [12] studied the effects of the viscous and Joule heating on MHD free convection flows with variable plate temperatures in a micropolar fluid. Sharma and Thakur [13] studied the effects of MHD on a couple stress fluid heated from below in a porous medium. Sharma and Sharma [14] discussed effects of the thermosolutal convection of micropolar fluids with MHD through a porous medium. El-Amin [15] considered the MHD free convection and mass transfer flow in a micropolar fluid over a stationary vertical plate with a constant suction. Kim [16] analyzed the unsteady MHD heat mass transfer convection flow of polar fluids past a vertical moving porous plate in a porous medium. Ibrahim et al. [17] examined the effects of an unsteady MHD micropolar fluid flow over a vertical porous plate through a porous medium in the presence of thermal and mass diffusion with a constant heat source. Rehman and Sattar [18] analyzed the effects of magnetohydrodynamic convective flow of a micropolar fluid past a continuously moving porous plate in the presence of heat generation/absorption. Ahmed et al. [19] investigated an unsteady MHD free convective flow past a vertical porous plate immersed in a porous medium with Hall current, thermal diffusion and heat transfer.

At the macroscopic level, it is well accepted that the boundary condition for a viscous fluid at a solid wall is one of no-slip, i.e., the fluid velocity matches the velocity of the solid boundary. While the no-slip condition has been processed experimentally to be accurate for a number of macroscopic flows, it remains an assumption that it is not based on physical principles. In many practical applications, the particle adjacent to a solid surface no longer takes the velocity of the surface. The particle at the surface has a finite tangential velocity. It slips along the surface. The flow regime is called a slip flow regime, and this effect cannot be neglected. The study of magneto-polar fluid flows in the slip-flow regimes with heat transfer has important engineering applications, e.g., in power generators, refrigeration coils, transmission lines, electric transformers, and heating elements. Khandelwal et al. [20] studied the effects of permeability variation on the MHD unsteady flow of a polar fluid through a porous medium in a slip-flow regime over an infinite porous flat plate. Sharma and Chaudhary [21] studied the effect of variable suction on transient free convective viscous incompressible flows past a vertical plate in a slip-flow regime. Sharma [22] investigated the effects of periodic temperature and concentration on the unsteady free stream consisting of a mean velocity over which a velocity exponentially varying with time is superimposed. Choudhary and Jha [23] studied effects of chemical reaction on an MHD micropolar fluid in slip flow regime. Mishra et al. [24] investigated the mass transfer effect on a free convective flow through a porous medium in the slip flow regime. An analytical solution to the MHD micropolar fluid flow past a vertical plate in a slip-flow regime in the presence of thermal diffusion and thermal radiation was investigated by Oahimire et al. [25]. In the present analysis, we study the effects of variable permeability on an MHD magnetopolar fluid past a vertical plate in the slip flow regime.

\section{Formulation of the problem}

We consider a two dimensional flow of a polar fluid past a semi-infinite vertical plate embedded in a porous medium in the slip-flow regime. The $x$-axis is taken along the porous plate in the upward direction and the $y$-axis normal to it. Due to the semi-infinite plane surface assumption, the flow variables are the functions of $y$ and $t$ only. To derive the basic equations for the problem under consideration, the following assumptions are made:

(i) The flow is unsteady, viscous, incompressible and electrically conducting with constant physical properties.

(ii) The magnetic Reynolds number is assumed to be small enough so that the induced magnetic field can be neglected.

(iii) The effect of the viscous dissipation is negligible in the energy equation.

(iv) It is also assumed that there is no applied voltage, which implies the absence of an electric field.

Under these assumptions, introducing dimensional quantities, the governing equations for the flow are as follows. 


$$
\frac{\partial v^{*}}{\partial y^{*}}=0
$$

Linear momentum equation

$$
\frac{\partial u^{*}}{\partial t^{*}}+v^{*} \frac{\partial u^{*}}{\partial y^{*}}=-\frac{1}{\rho} \frac{\partial p^{*}}{\partial x^{*}}+\left(\mathrm{v}+\mathrm{v}_{r}\right) \frac{\partial^{2} u^{*}}{\partial y^{* 2}}+2 \mathrm{v}_{r} \frac{\partial \omega^{*}}{\partial y^{*}}-\frac{\mathrm{v}}{K^{*}} u^{*}-\frac{\sigma B_{0}{ }^{2} u^{*}}{\rho}+g \beta\left(T^{*}-T_{\infty}^{*}\right) .
$$

Angular momentum equation

$$
\frac{\partial \omega^{*}}{\partial t^{*}}+v^{*} \frac{\partial \omega^{*}}{\partial y^{*}}=\frac{\gamma}{I} \frac{\partial^{2} \omega^{*}}{\partial y^{* 2}}
$$

Energy equation

$$
\frac{\partial \omega^{*}}{\partial t^{*}}+v^{*} \frac{\partial \omega^{*}}{\partial y^{*}}=\frac{\gamma}{I} \frac{\partial^{2} \omega^{*}}{\partial y^{* 2}}
$$

Appropriate boundary conditions are

$$
\begin{aligned}
& u^{*}=U_{0}+L_{1}{ }^{*} \frac{\partial u^{*}}{\partial y^{*}}, \quad T^{*}=T_{w}^{*}, \quad \frac{\partial \omega^{*}}{\partial y^{*}}=-\frac{\partial^{2} u^{*}}{\partial y^{* 2}} \quad \text { at } \quad y^{*}=0, \\
& u^{*}=U_{0}\left(1+\varepsilon e^{-n t}\right), \quad T^{*} \rightarrow T_{\infty}{ }^{*}, \quad \omega^{*} \rightarrow 0 \quad \text { at } \quad y^{*}=\infty .
\end{aligned}
$$

From the continuity Eq.(2.1), the suction normal to the plate can be written as

$$
v^{*}=-V_{0}\left(1+A \varepsilon e^{-n t}\right)
$$

where $A$ is a real positive constant and $\varepsilon A$ is less than unity; $V_{0}$ is the scale of the suction velocity which has a non zero positive constant.

We introduce the following non-dimensional quantities

$$
\begin{aligned}
& u=\frac{u^{*}}{U_{0}}, \quad t=\frac{t^{*} V_{0}{ }^{2}}{v}, \quad x=\frac{x^{*} U_{0}}{v}, \quad y=\frac{y^{*} V_{0}}{v}, \quad p=\frac{p^{*}}{\rho V_{0}{ }^{2}}, \\
& \omega=\frac{\omega^{*} v}{V_{0} U_{0}}, \quad K=\frac{K^{*} V_{0}^{2}}{v^{2}}, \quad \theta=\frac{T^{*}-T_{\infty}{ }^{*}}{T_{w}{ }^{*}-T_{\infty}{ }^{*}}, \quad M^{2}=\frac{\sigma B_{0}{ }^{2} \mathrm{v}}{\rho V_{0}^{2}}, \\
& \mathrm{Gr}=\frac{g \beta\left(T_{w}{ }^{*}-T_{\infty}{ }^{*}\right) \mathrm{v}}{V_{0}{ }^{2} U_{0}}, \quad \alpha=\frac{\mathrm{v}_{r}}{\mathrm{v}}, \quad \operatorname{Pr}=\frac{v \rho C_{p}}{k}, \quad \frac{\gamma}{I v}=\frac{1}{\beta}, \\
& K=K_{0}\left(1+A \varepsilon e^{-n t}\right), \quad N=M^{2}+\frac{1}{K_{0}\left(1+A \varepsilon e^{-n t}\right)}, \quad u=U_{0}\left(1+\varepsilon e^{-n t}\right) .
\end{aligned}
$$


form

In view of Eqs (2.6) - (2.7), the governing Eqs (2.2) - (2.4) reduce to the following dimensionless

$$
\begin{aligned}
& \frac{\partial^{2} u}{\partial y^{2}}+K_{1} \frac{\partial u}{\partial y}+A K_{l} \varepsilon e^{-n t} \frac{\partial u}{\partial y}+K_{2} \frac{\partial \omega}{\partial y}-K_{3}(u-U)-K_{1} \frac{\partial u}{\partial t}=-K_{1} \frac{\partial U}{\partial t}-K_{l} \operatorname{Gr} \theta \\
& \frac{\partial^{2} \omega}{\partial y^{2}}+\beta \frac{\partial \omega}{\partial y}+\beta A \varepsilon e^{-n t} \frac{\partial \omega}{\partial y}=\beta \frac{\partial \omega}{\partial t}, \\
& \frac{\partial^{2} \theta}{\partial y^{2}}+\operatorname{Pr} \frac{\partial \theta}{\partial y}+A \operatorname{Pr} \varepsilon e^{-n t} \frac{\partial \theta}{\partial y}=\operatorname{Pr} \frac{\partial \theta}{\partial t} .
\end{aligned}
$$

And the corresponding boundary conditions (2.5) are

$$
\begin{aligned}
& u=0, \quad \frac{\partial \omega}{\partial y^{\backslash}}=-\frac{\partial^{2} u}{\partial y^{2}}, \quad \theta \rightarrow 1 \quad \text { at } \quad y=0, \\
& u=\left(1+\varepsilon e^{-n t}\right), \quad \omega \rightarrow 0, \quad \theta \rightarrow 0 \quad \text { at } \quad y \rightarrow \infty .
\end{aligned}
$$

\section{Solution of the problem}

Let us assume $u, \omega$ and $\theta$ as

$$
\begin{aligned}
& u(y, t)=u_{0}(y)+\varepsilon e^{-n t} u_{l}(y), \\
& \omega(y, t)=\omega_{0}(y)+\varepsilon e^{-n t} \omega_{l}(y), \\
& \theta(y, t)=\theta_{0}(y)+\varepsilon e^{-n t} \theta_{l}(y) .
\end{aligned}
$$

By substituting the above Eqs (3.1) to (3.3) into Eqs (2.8) to (2.10), neglecting the coefficient of $\varepsilon^{2}$, we obtain the following pair of equations for $\left(u_{0}, u_{1}\right),\left(\omega_{0}, \omega_{1}\right),\left(\theta_{0}, \theta_{1}\right)$

$$
\begin{aligned}
& \frac{\partial^{2} u_{0}}{\partial y^{2}}+K_{1} \frac{\partial u_{0}}{\partial y}-K_{3} u_{0}=-K 3-K_{2} \frac{\partial \omega_{0}}{\partial y}-K_{1} \mathrm{Gr} \theta_{0} \\
& \frac{\partial^{2} u_{1}}{\partial y^{2}}+K_{1} \frac{\partial u_{1}}{\partial y}+K_{4} u_{1}=K_{4}-K_{2} \frac{\partial \omega_{1}}{\partial y}-A K_{1} \frac{\partial u_{0}}{\partial y}-K_{1} \operatorname{Gr} \theta_{1} \\
& \frac{\partial^{2} \omega_{0}}{\partial y^{2}}+\beta \frac{\partial \omega_{0}}{\partial y}=0 \\
& \frac{\partial^{2} \omega_{1}}{\partial y^{2}}+\beta \frac{\partial \omega_{1}}{\partial y}+n \beta \omega_{1}=-\beta A \frac{\partial \omega_{0}}{\partial y} \\
& \frac{\partial^{2} \theta_{0}}{\partial y^{2}}+\operatorname{Pr} \frac{\partial \theta_{0}}{\partial y}=0
\end{aligned}
$$




$$
\frac{\partial^{2} \theta_{1}}{\partial y^{2}}+\operatorname{Pr} \frac{\partial \theta_{1}}{\partial y}+n \operatorname{Pr} \theta_{1}=A \operatorname{Pr}^{2} e^{-\operatorname{Pr} y}
$$

The solution of Eqs (3.4) - (3.9) satisfying the boundary conditions (2.11) are given by

$$
\begin{aligned}
& u_{0}=C_{7} e^{-K_{7} y}+C_{5} K_{8} e^{-\beta y}+K_{9} e^{-\operatorname{Pr} y}+1, \\
& u_{1}=C_{8} e^{-K_{10} y}+K_{11} C_{6} e^{-K_{6} y}+K_{12} C_{5} e^{-\beta y}+K_{13} C_{7} e^{-K_{7} y}+ \\
& +K_{14} C_{5} e^{-\beta y}+K_{15} e^{-\operatorname{Pr} y}+K_{16} e^{-K_{5} y}-K_{17} \operatorname{Pr} e^{-\operatorname{Pr} y}, \\
& \omega_{0}=C_{4}+C_{5} e^{-\beta y}, \\
& \omega_{1}=C_{6} e^{-K_{6} y}+\frac{A}{n} \beta C_{5} e^{-\beta y}, \\
& \theta_{0}=C_{1}+C_{2} e^{-\operatorname{Pr} y}, \\
& \theta_{1}=C_{3} e^{-K_{5} y}+\frac{A}{n} \operatorname{Pr} e^{-\operatorname{Pr} y} .
\end{aligned}
$$

The constants are given in Appendix.

\section{Result and discussions}

The formulation of the MHD convective flow and mass transfer of an incompressible micropolar fluid along a semi infinite vertical plate in a porous medium has been carried out in the preceding sections. This enables us to carry out the numerical calculations for the distribution of the translation velocity, microrotation, temperature and concentration across the boundary layer for various values of the parameter. In the present study, we have chosen $t=1, \varepsilon=0.2, A=0.5$, while $n, \beta, M, \mathrm{Gr}, K, \operatorname{Pr}, \alpha$, and h are varied over a range as listed in the figures.

The effects of the kinematic rotational viscosity parameter $(\alpha)$ on the translational velocity and microrotation profiles across the boundary are presented in Figs 1a and 1b. It is noted that the translational velocity and microrotation distribution show an accelerating nature near the plate as $\alpha$ increases, and then decays to the relevant free stream velocity. For different values of the couple stress parameter $(\beta)$, the translational velocity and microrotation profiles are plotted in Figs $2 \mathrm{a}$ and $2 \mathrm{~b}$. It is observed that the translation velocity and microrotation profile increase with increasing the value of the couple stress parameter $(\beta)$. For the various values of the permeability parameter $K$ the profiles of the translation velocity and microrotaion across the boundary layer are shown in Figs $3 \mathrm{a}$ and $3 \mathrm{~b}$. The translation velocity increases as $K$ increases but as the permeability parameter increases microrotation tends to decrease. Figures $4 \mathrm{a}$ and $4 \mathrm{~b}$ depict the velocity and microrotation for different values of the slip flow parameter $h$. It can be observed that velocity increases with an increasing value of the slip flow parameter $h$ while a reverse effect is observed for microrotation. For different values of the magnetic field parameter $M$ the translation velocity and microrotation profile are plotted in Figs $5 \mathrm{a}$ and $5 \mathrm{~b}$. It is obvious that the effect of increasing value of the parameter $M$ results in a decreasing velocity distribution across the boundary layer while a reverse phenomenon occurs for the microrotation profile. Figures $6 a, b$ and $7 a, b$ present the velocity and microrotation for different values of the Prandtl number Pr and Grashof numbers, respectively. The result shows that the effect of increasing Pr and Gr results in a decrease in the velocity, while a reverse effect is observed for microrotation. Figure 8a shows the skin friction coefficient with the variation of parameter $h$. It is noted that an 
increase of the kinematic rotational viscosity parameter $(\alpha)$ increases the skin friction coefficient whereas the skin friction coefficient decreases for increasing values of $\beta, n$ and $K$. The values of the wall couple stress coefficient with variation $\mathrm{h}$ are shown in Fig. $8 \mathrm{a}$ and in $8 \mathrm{~b}$ the results show that increase in $\alpha$, and $K$, the couple stress coefficient increases an increase in $\beta$ and $n$ results in a decrease of couple stress coefficient. Figure 9 illustrates the variation of temperature profiles for different values of the Prandtl number Pr. The results show that an increase of the Prandtl number results in a decrease in the thermal boundary layer thickness. The reason is that small values of Pr are equivalent to increasing the thermal conductivities and therefore heat is able to diffuse away from the heated surface more rapidly than for larger values of Pr.

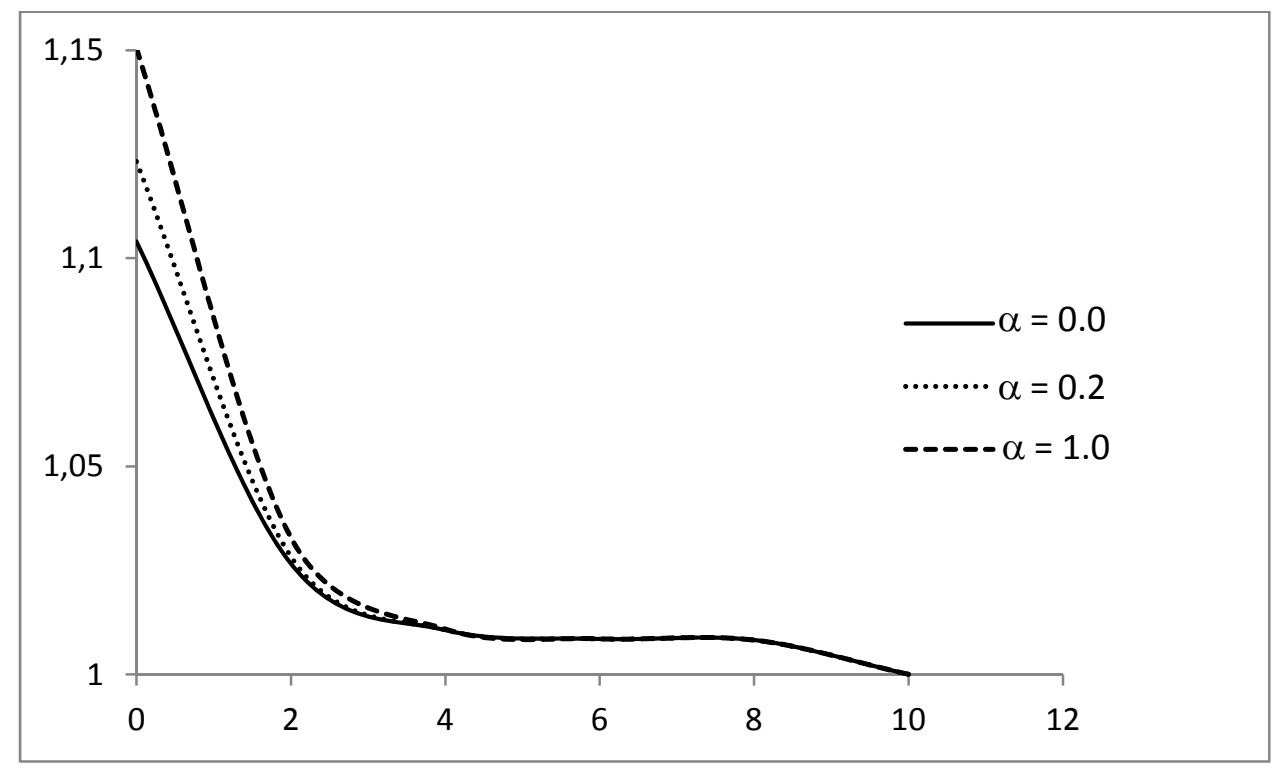

Fig.1a. Velocity profiles for various values of $\alpha$ with $\beta=2.0, M=2.0, K=1, \operatorname{Pr}=1, t=1.0, \varepsilon=0.2$, $A=0.4, h=0.4, \mathrm{Gr}=2.0, n=0.1$.

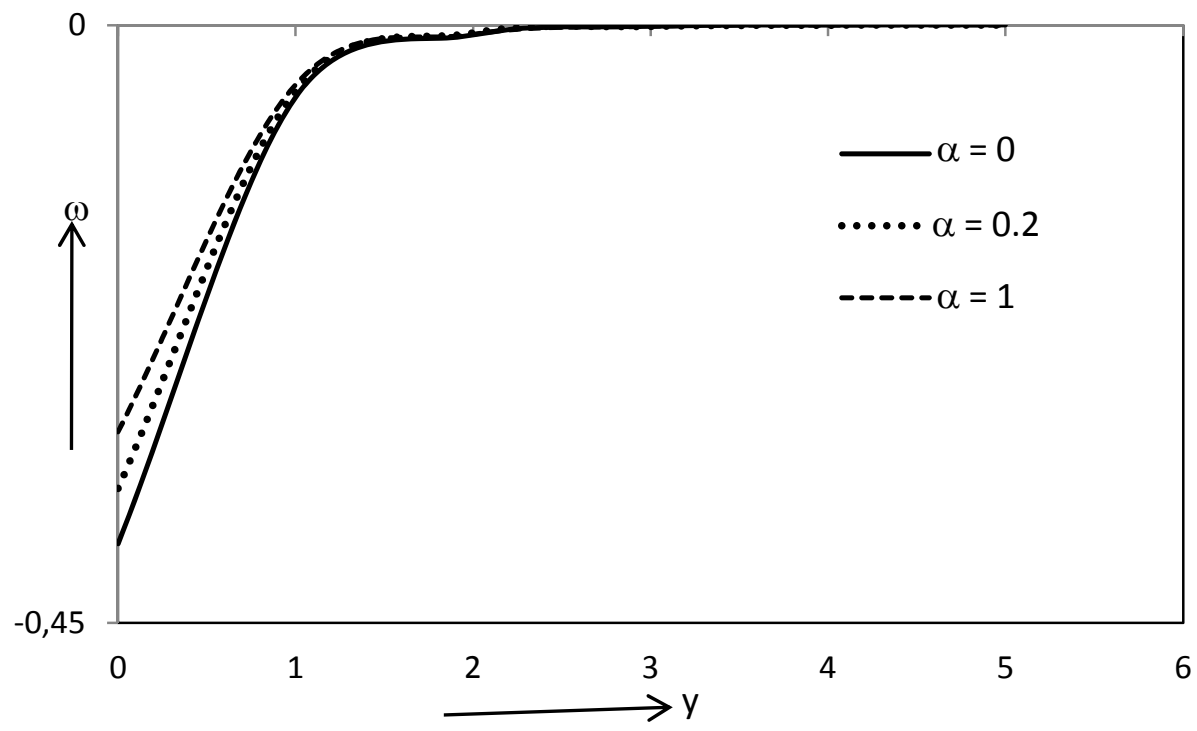

Fig.1b. Microrotation profiles for various values of $\alpha$ with $\beta=2.0, M=2.0, K=1, \operatorname{Pr}=1, t=1.0, \varepsilon=0.2$, $A=0.4, h=0.4, \mathrm{Gr}=2.0, n=0.1$. 


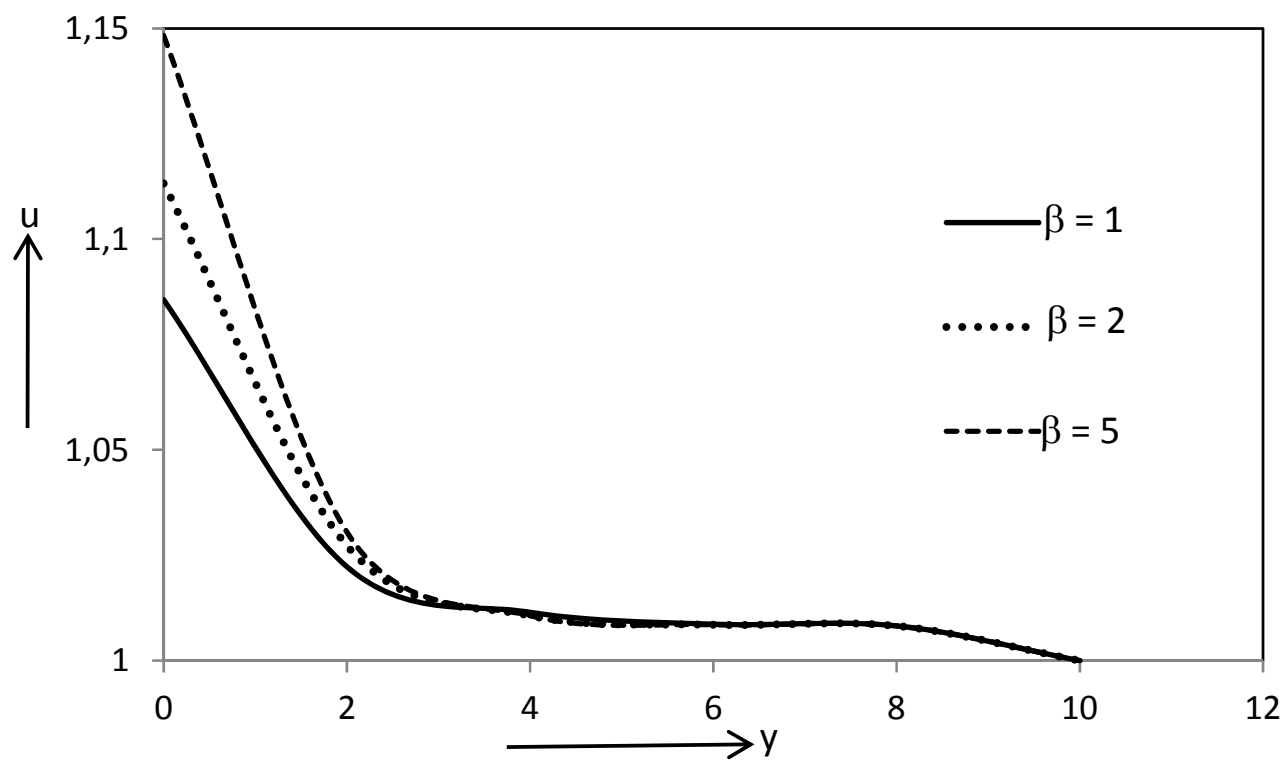

Fig.2a. Velocity profiles for various values of $\beta$ with $\alpha=0.2, M=2.0, K=1, \operatorname{Pr}=1, t=1.0, \varepsilon=0.2$, $A=0.4, h=0.4, \mathrm{Gr}=2.0, n=0.1$.

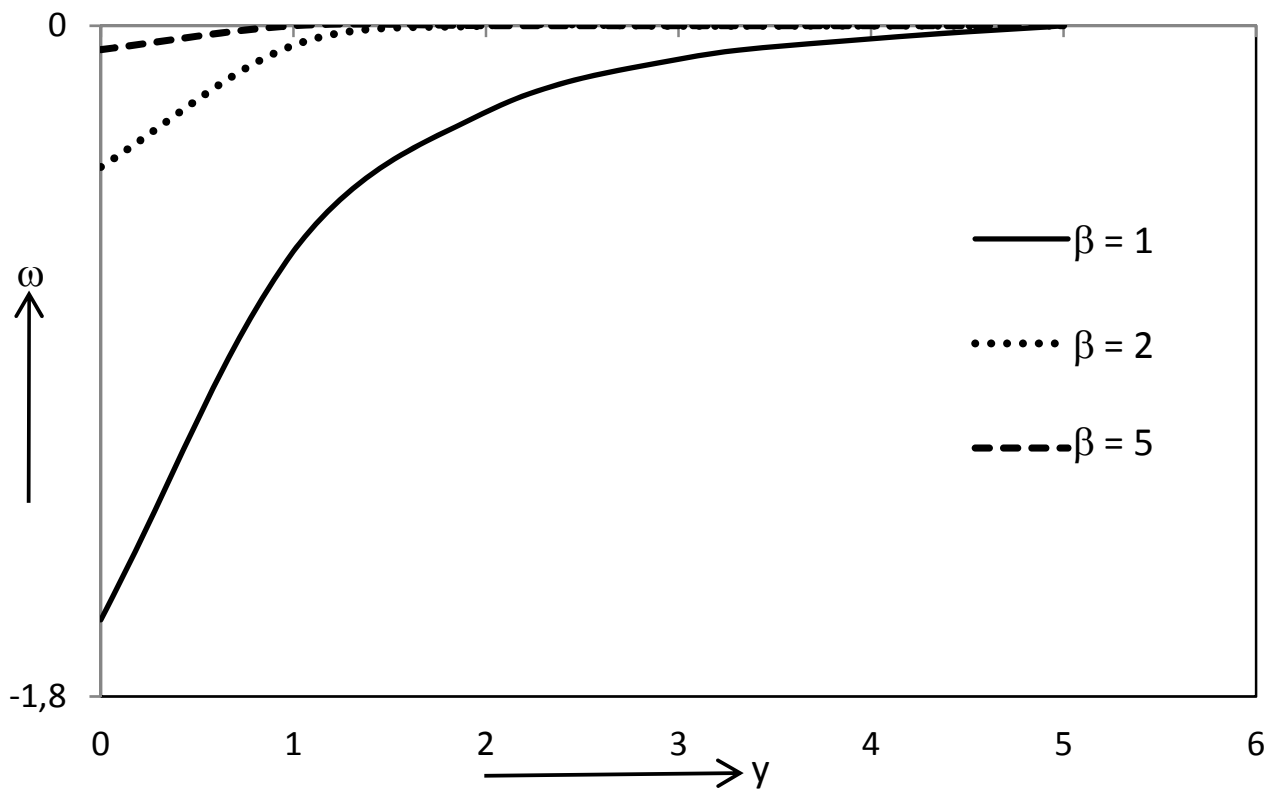

Fig.2b. Microrotation profiles for various values of $\beta$ with $\alpha=0.2, M=2.0, K=1, \operatorname{Pr}=1, t=1.0, \varepsilon=0.2$, $A=0.4, h=0.4, \mathrm{Gr}=2.0, n=0.1$. 


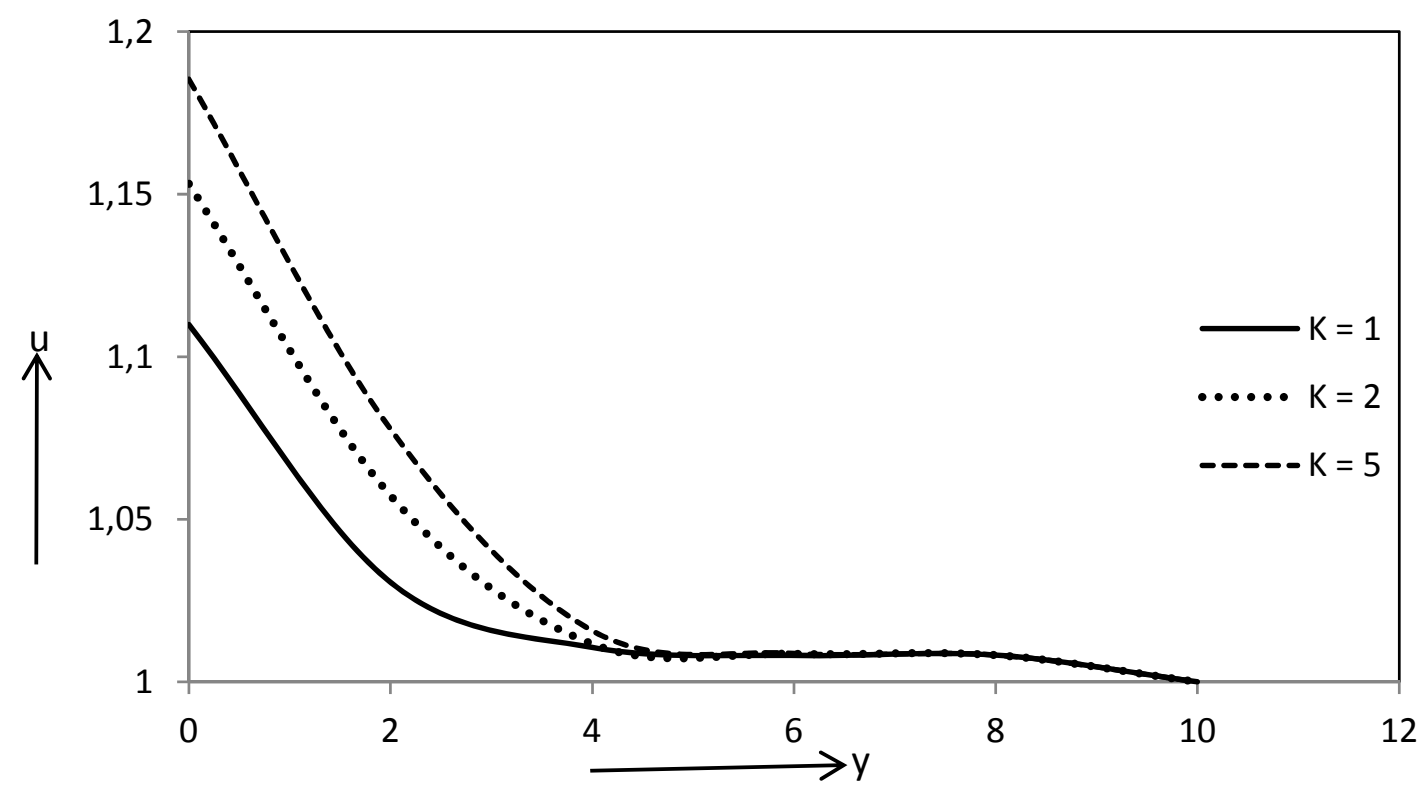

Fig.3a. Velocity profiles for various values of $K$ with $\beta=2.0, M=2.0, \operatorname{Pr}=1, \alpha=0.2, t=1.0, \varepsilon=0.2$, $A=0.4, h=0.4, \mathrm{Gr}=2.0, n=0.1$.

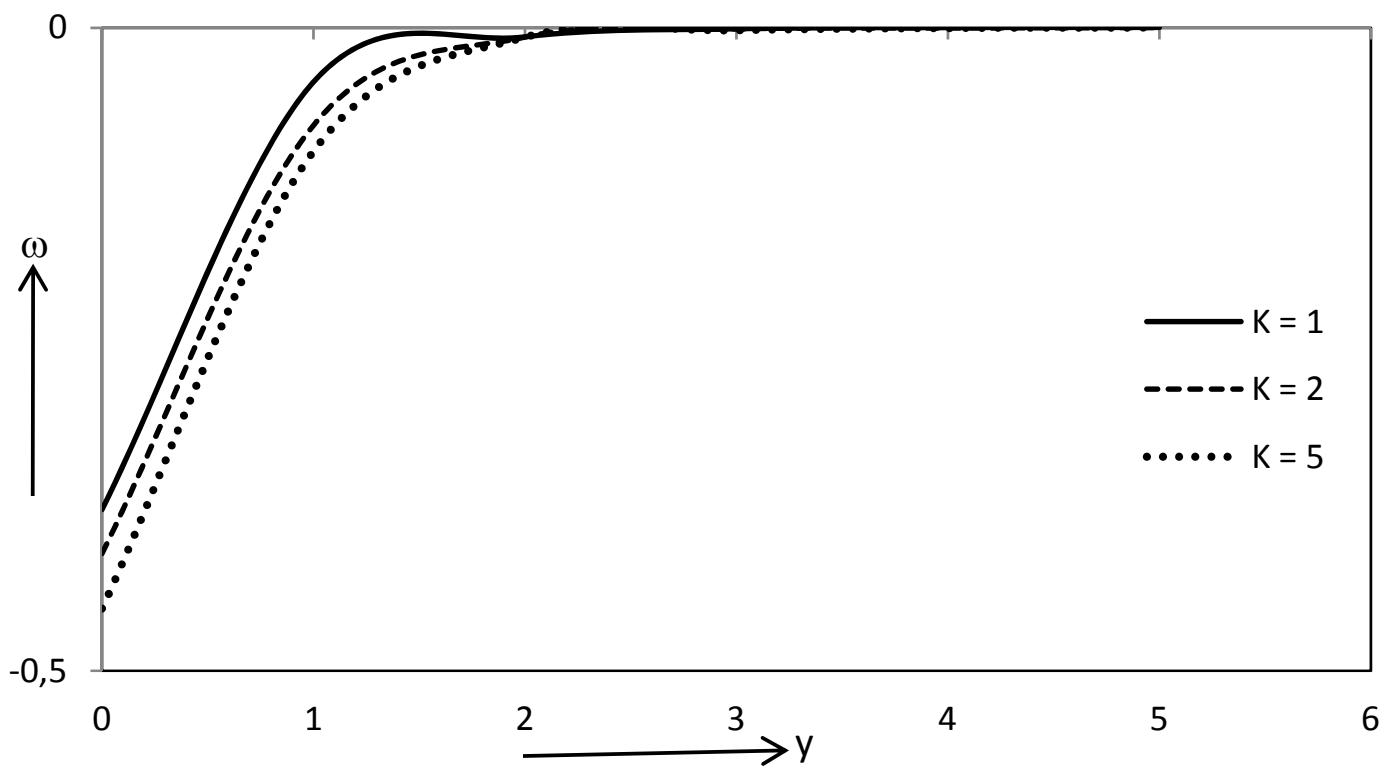

Fig.3b. Microrotation profiles for various values of $K$ with $\beta=2.0, M=2.0, \operatorname{Pr}=1, \alpha=0.2, t=1.0, \varepsilon=0.2$, $A=0.4, h=0.4, \mathrm{Gr}=2.0, n=0.1$. 


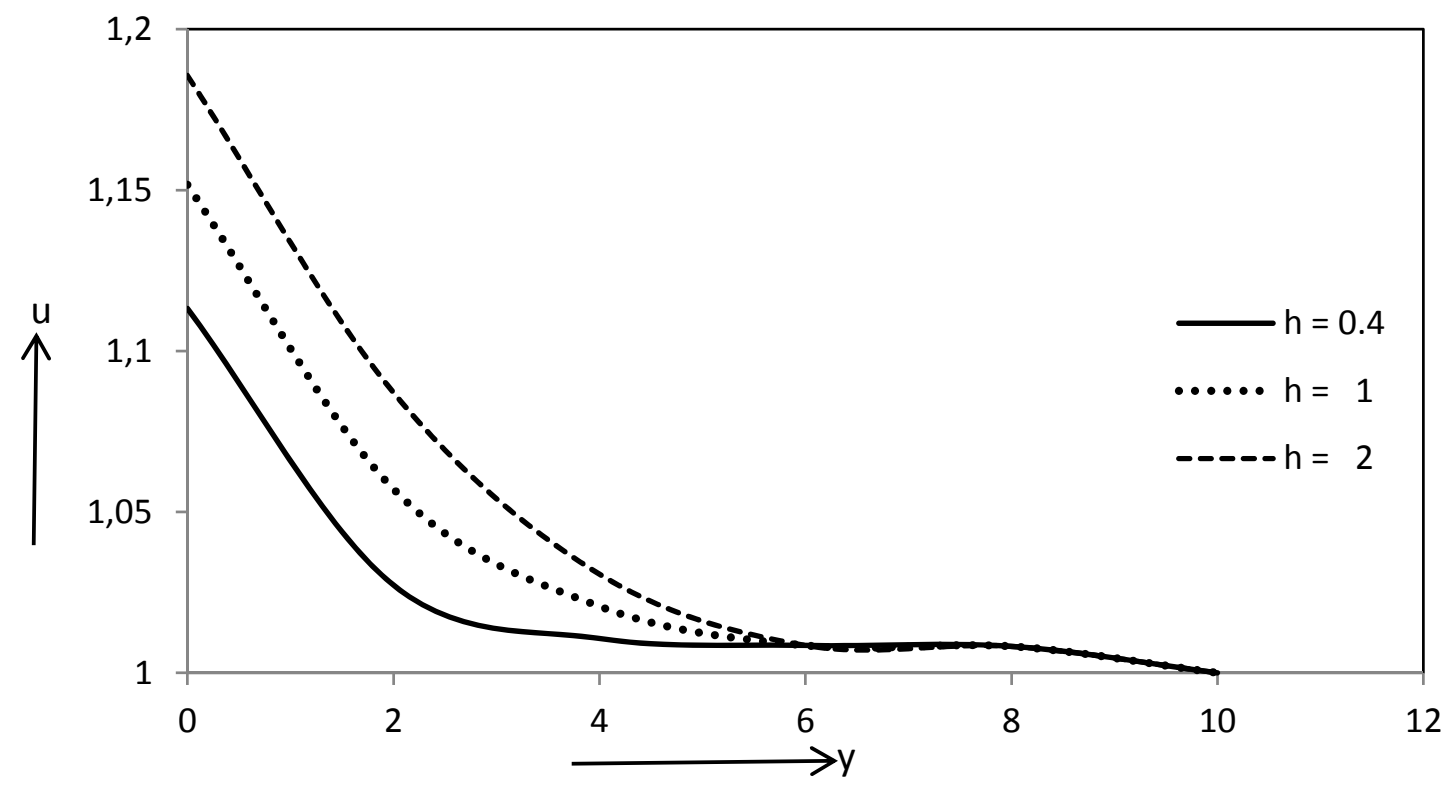

Fig.4a. Velocity profiles for various values of $h$ with $\beta=2.0, M=2.0, \operatorname{Pr}=1, \alpha=0.2, t=1.0, \varepsilon=0.2$, $A=0.4, K=1.0, \mathrm{Gr}=2.0, n=0.1$.

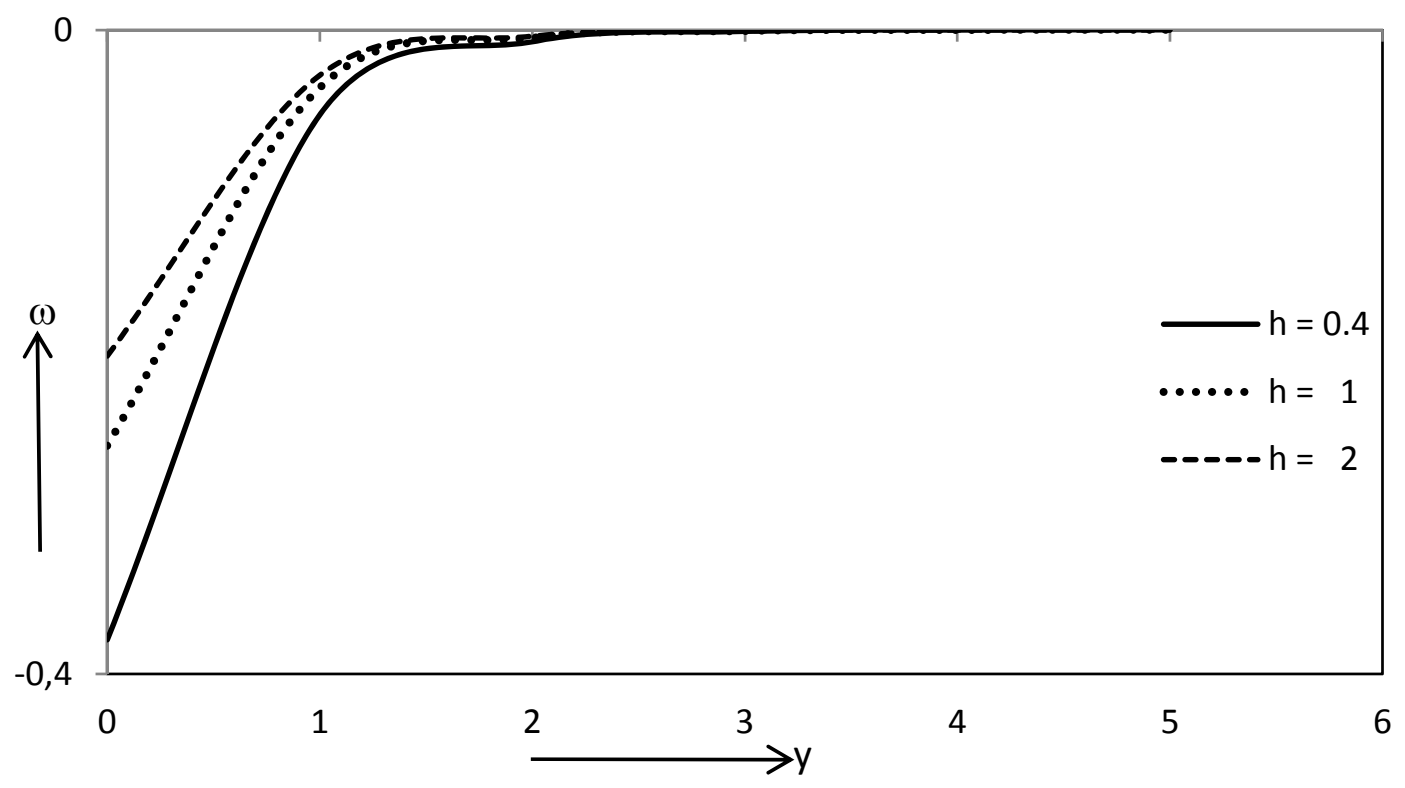

Fig.4b. Microrotation profiles for various values of $h$ with $\beta=2.0, M=2.0, \operatorname{Pr}=1, \alpha=0.2, t=1.0, \varepsilon=0.2$, $A=0.4, K=1.0, \mathrm{Gr}=2.0, n=0.1$. 


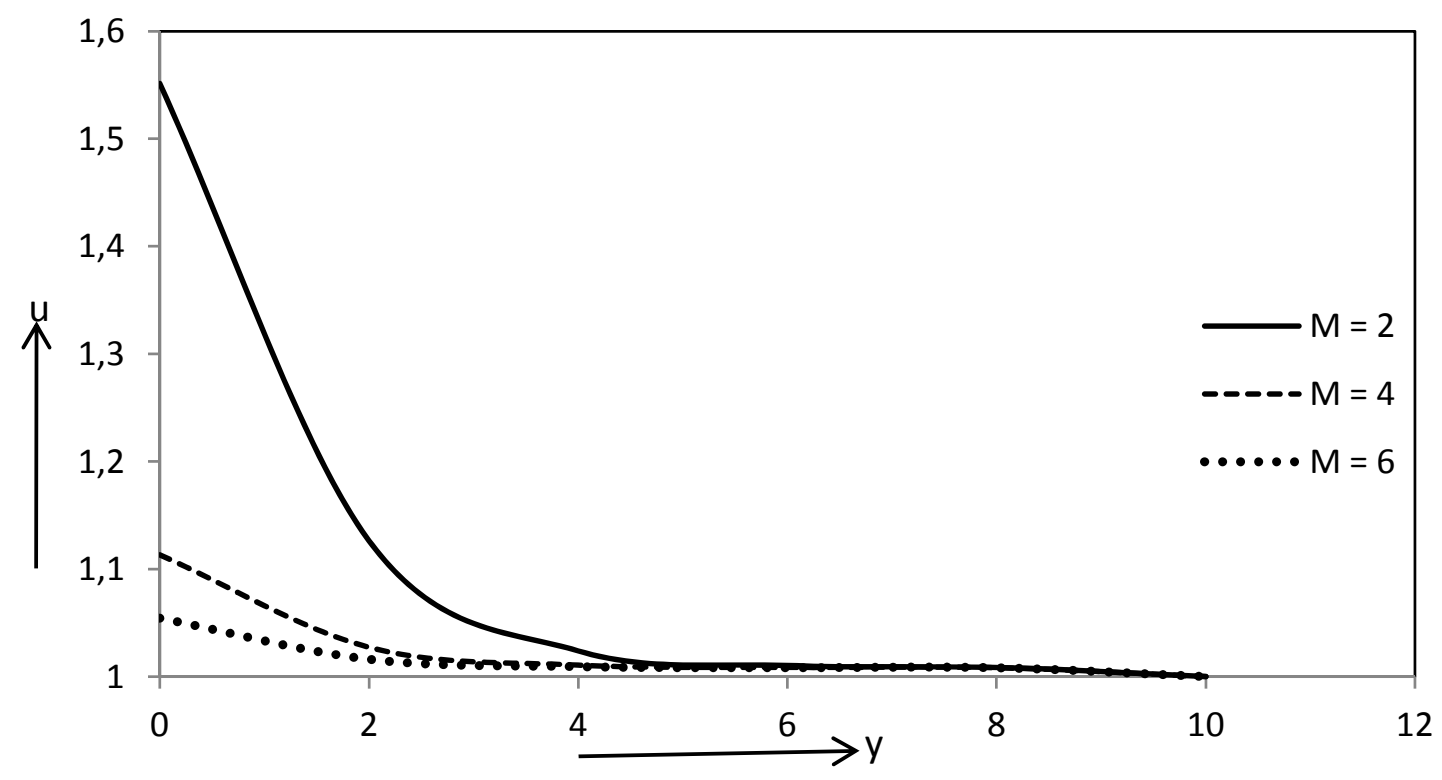

Fig.5a. Velocity profiles for various values of $M$ with $\beta=2.0, h=0.4, \operatorname{Pr}=1, \alpha=0.2, t=1.0, \varepsilon=0.2$, $A=0.4, K=1.0, \mathrm{Gr}=2.0, n=0.1$.

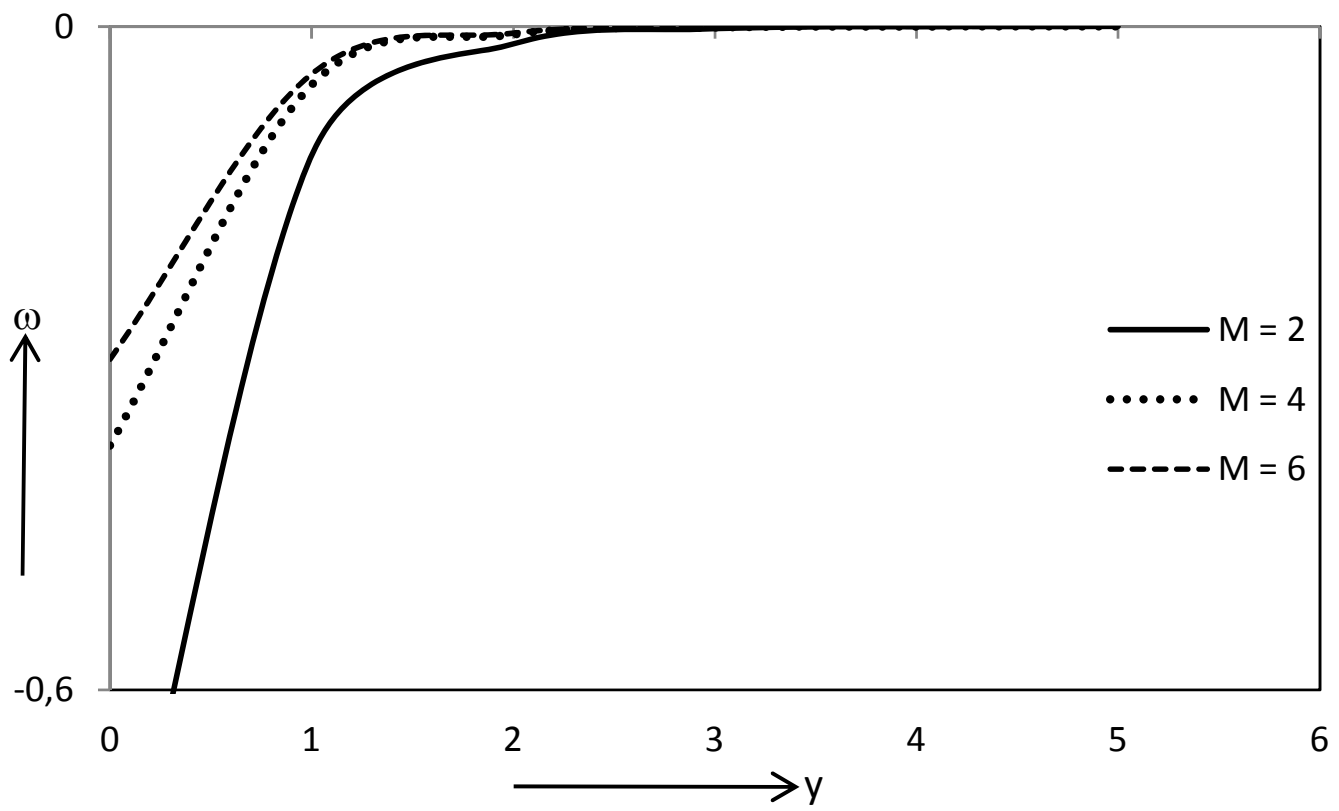

Fig.5b. Microrotation profiles for various values of $M$ with $\beta=2.0, h=0.4, \operatorname{Pr}=1, \alpha=0.2, t=1.0, \varepsilon=0.2$, $A=0.4, K=1.0, \mathrm{Gr}=2.0, n=0.1$. 


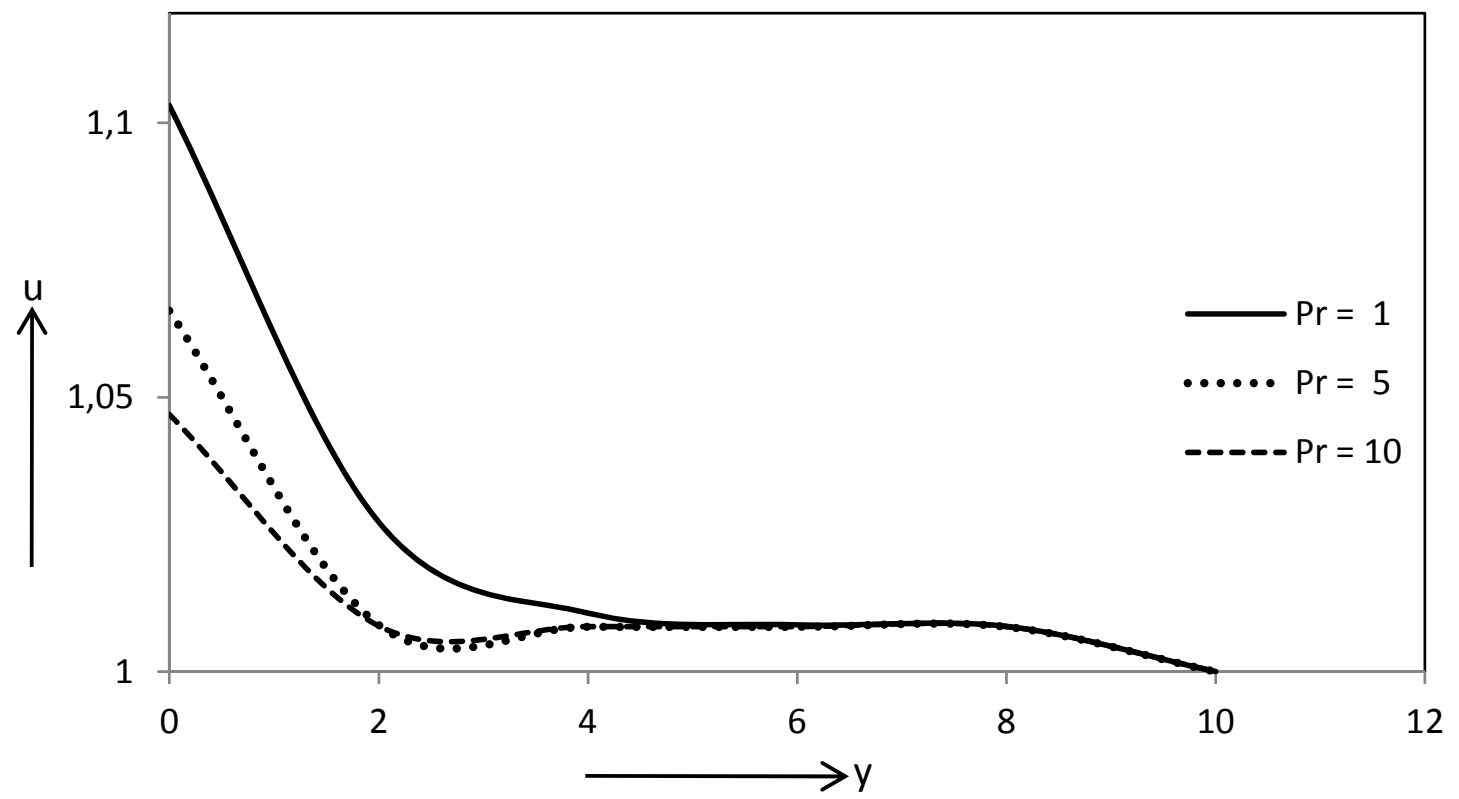

Fig.6a. Velocity profiles for various values of $\operatorname{Pr}$ with $\beta=2.0, h=0.4, M=2.0, \alpha=0.2, t=1.0, \varepsilon=0.2$, $A=0.4, K=1.0, \mathrm{Gr}=2.0, n=0.1$.

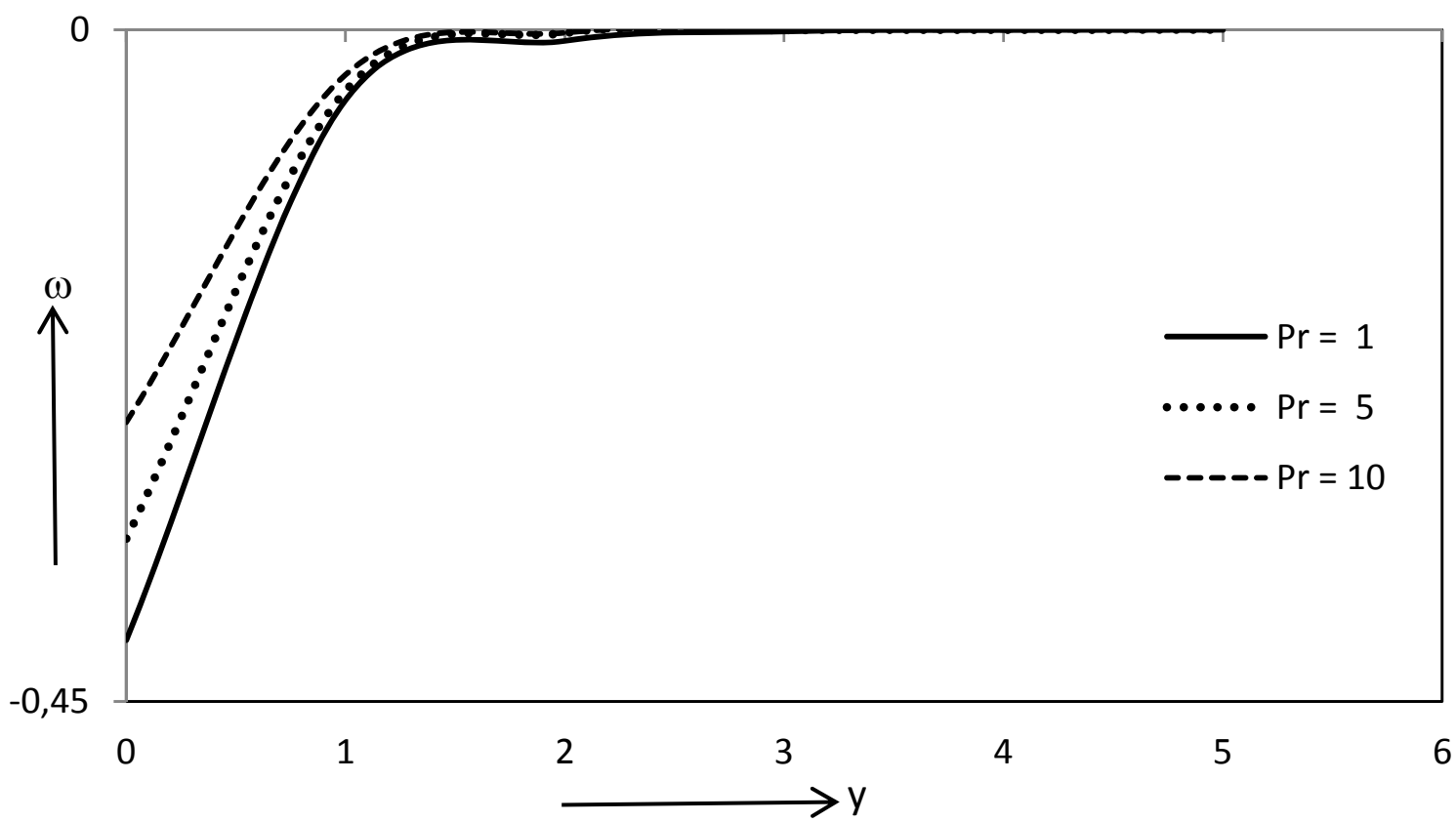

Fig.6b. Microrotation profiles for various values of $\operatorname{Pr}$ with $\beta=2.0, h=0.4, M=2.0, \alpha=0.2, t=1.0$, $\varepsilon=0.2, A=0.4, K=1.0, \mathrm{Gr}=2, n=0.1$. 


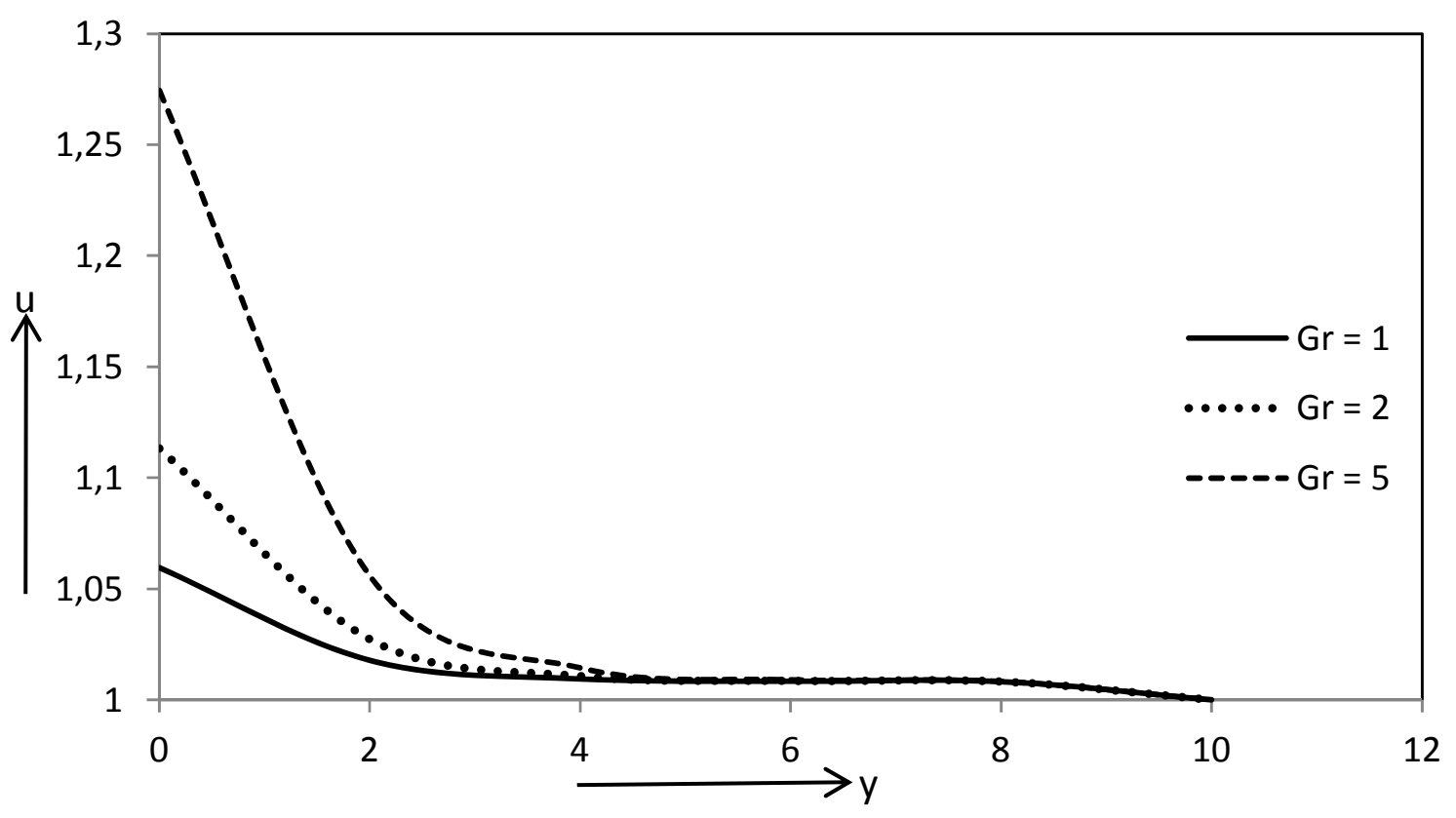

Fig.7a. Velocity profiles for various values of $\mathrm{Gr}$ with $\beta=2.0, h=0.4, M=2.0, \alpha=0.2, t=1.0, \varepsilon=0.2$, $A=0.4, K=1.0, \operatorname{Pr}=1, n=0.1$.

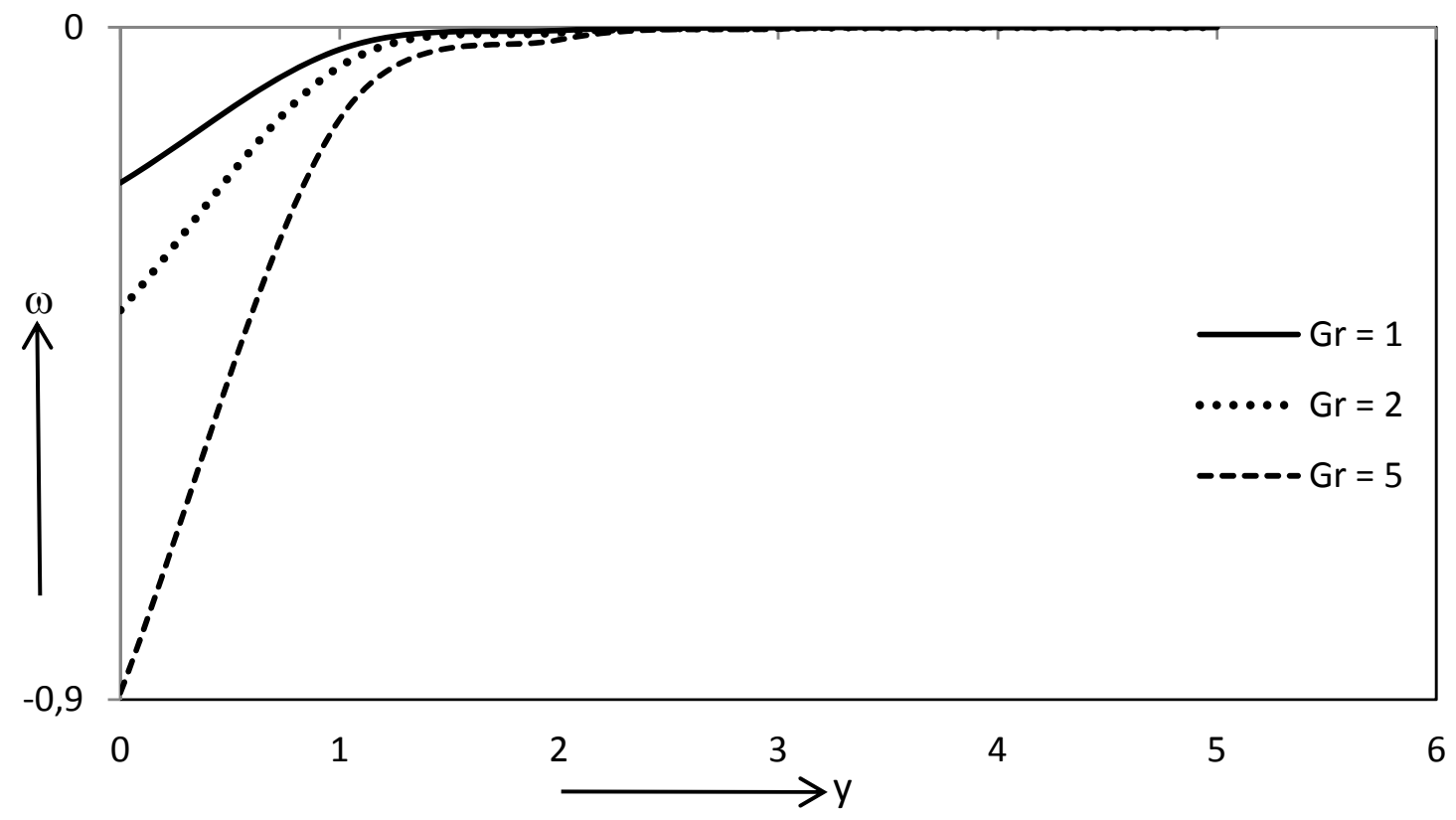

Fig.7b. Microrotation profiles for various values of $\mathrm{Gr}$ with $\beta=2.0, h=0.4, M=2.0, \alpha=0.2, t=1.0$, $\varepsilon=0.2, A=0.4, K=1.0, \operatorname{Pr}=1, n=0.1$. 


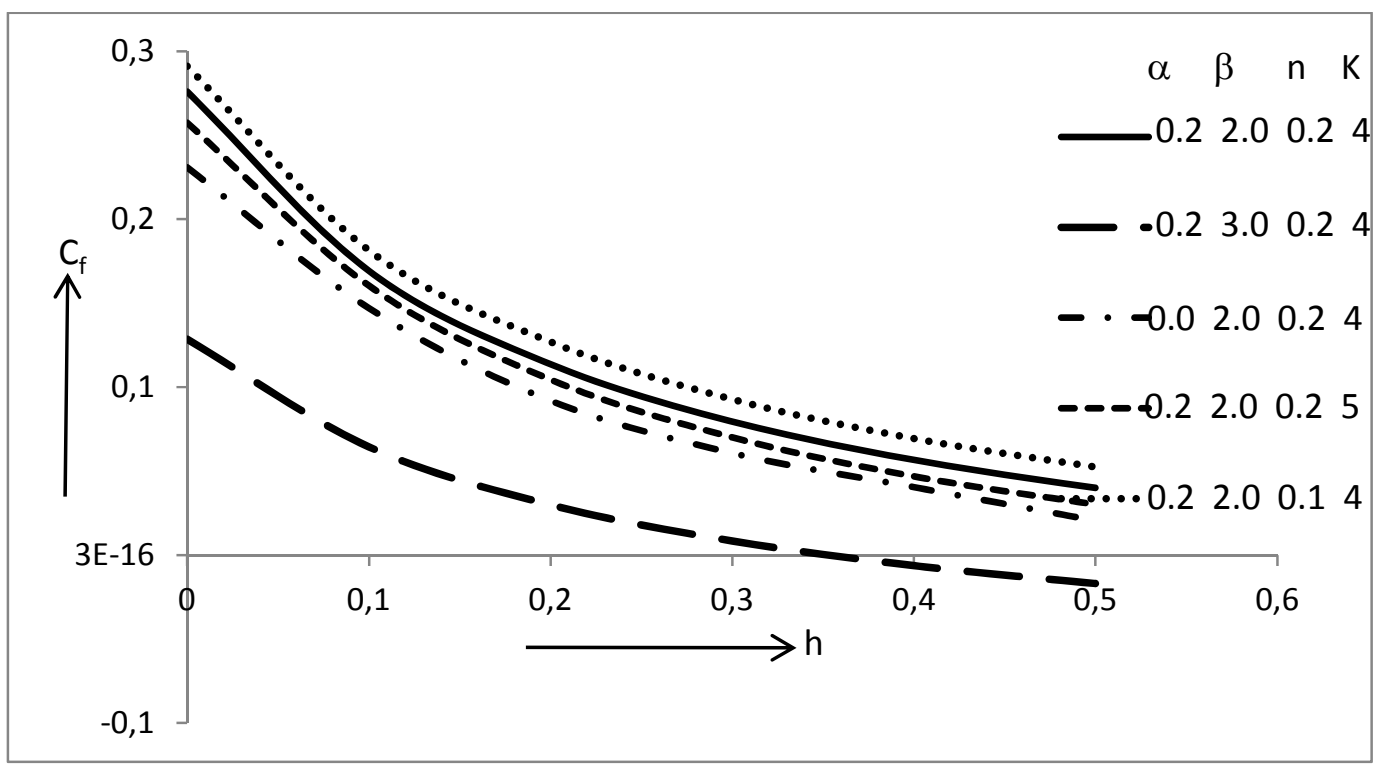

Fig.8a. Skin friction coefficient for various values of $h$ with $M=2.0, t=1.0, \varepsilon=0.2, A=0.4, \operatorname{Pr}=1.0$, $\mathrm{Gr}=2.0$.

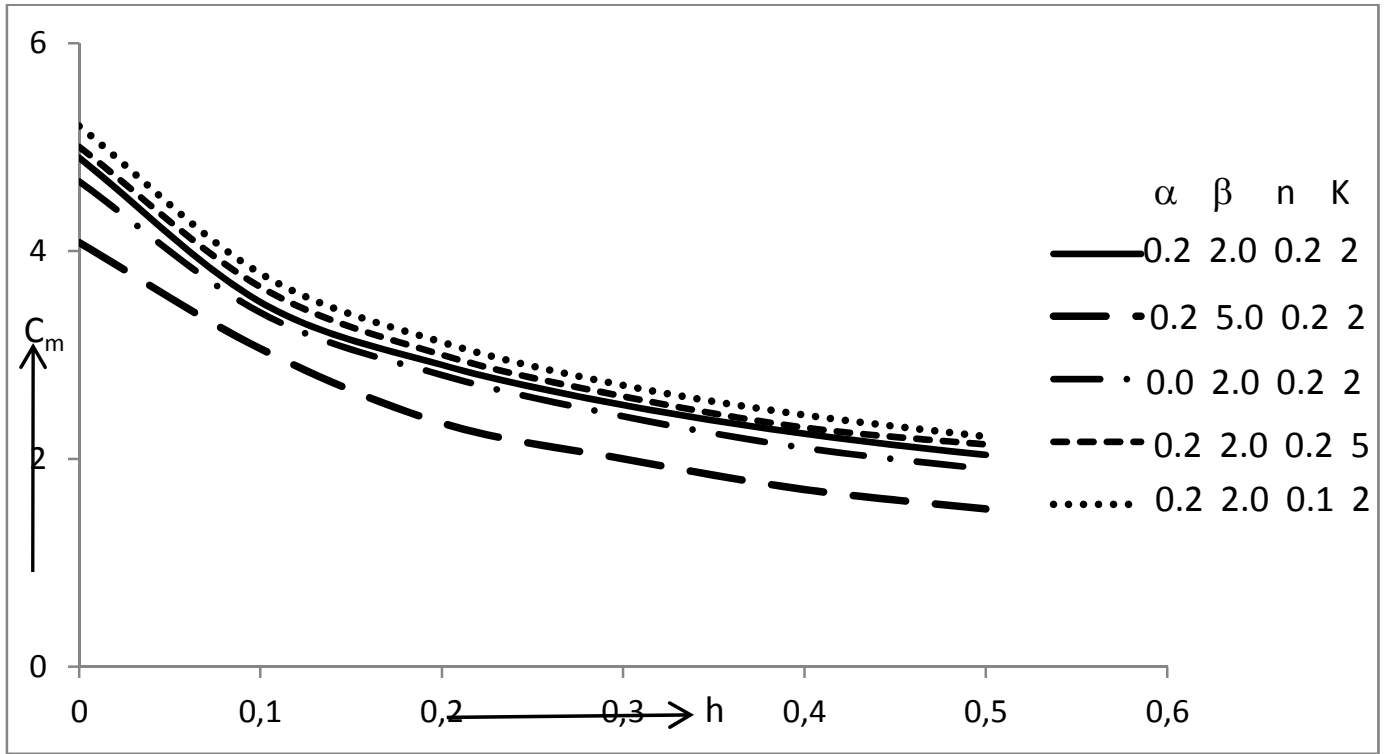

Fig.8b. Couple stress coefficient for various values of $h$ with $t=1.0, \varepsilon=0.2, A=0.4, \operatorname{Pr}=1.0, \mathrm{Gr}=2.0$, $M=2.0$. 


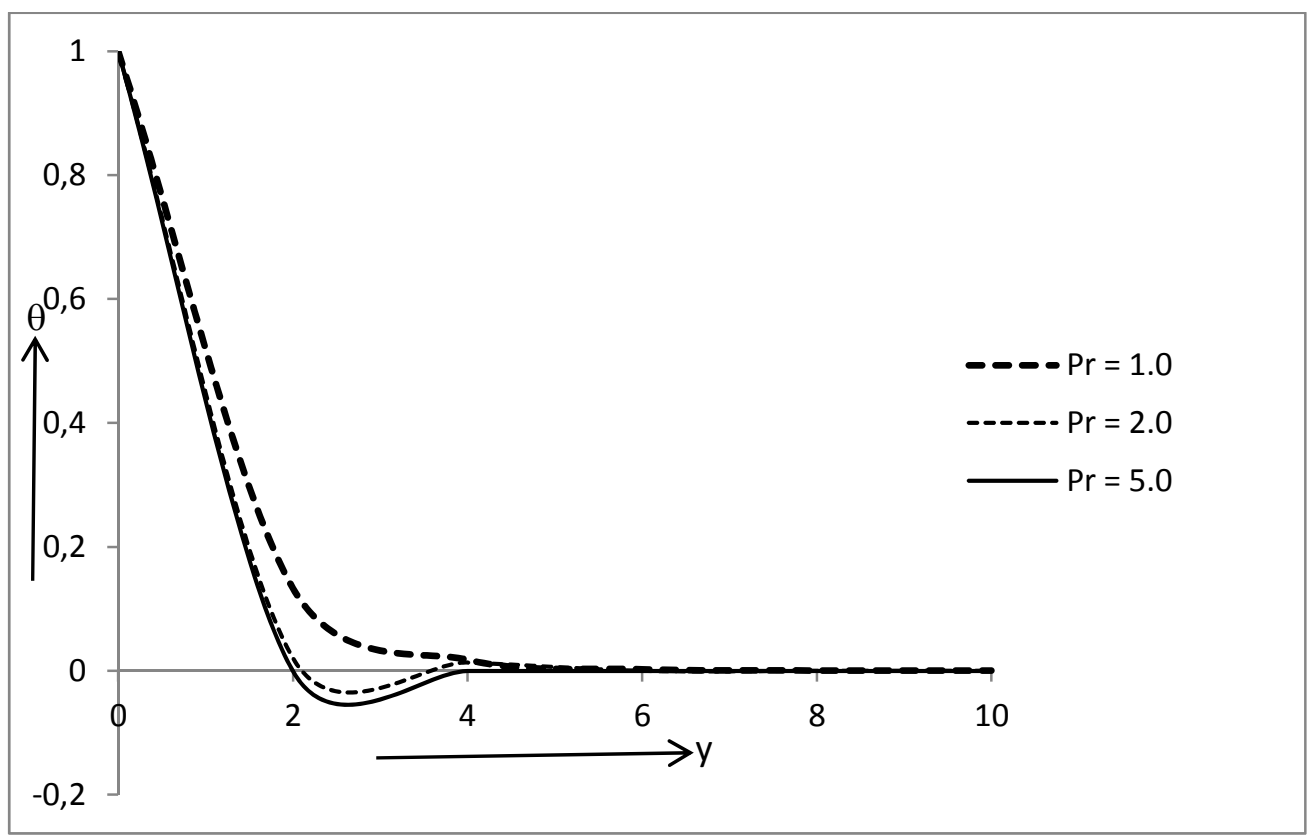

Fig.9. Temperature profiles for various values of $\operatorname{Pr}$ with $\beta=2.0, h=0.4, M=2.0, \alpha=0.2, t=1.0, \varepsilon=0.2$, $A=0.4, K=1, \operatorname{Pr}=1, n=0.1, \mathrm{Gr}=2.0$.

\section{Nomenclature}

$A$ - permeability amplitude

$B_{0}$ - magnetic induction

$C_{p}$ - specific heat at constant pressure

$\mathrm{Gr}$ - Grashof number

$g$ - gravitational acceleration

$h$ - slip flow parameter

$I$ - moment of inertia of unit mass

$K$ - permeability parameter

$K_{0}$ - mean permeability of the medium

$M$ - magnetic field parameter

$n$ - real constant

$P$ - pressure

Pr - Prandtl number

$T$ - temperature

$U_{0} \quad$ - scale of free stream velocity

$u, v$ - component of velocity along and perpendicular to the plate

$V_{0}$ - scale of the suction velocity

$x$ - distances along and perpendicular to the plate, respectively

$\alpha$ - rotational parameter

$\beta-$ couple stress parameter

$\gamma-$ spin gradient viscosity

$\theta$ - dimensionalless temperature

$\rho$ - density

$\sigma \quad-$ thermal conductivity 
v - fluid kinematic viscosity

$v_{r}-$ kinematic rotational viscosity

$\omega$ - mean angular velocity

\section{Subscripts}

$w$ - wall condition

$\infty$ - free stream condition

\section{Superscripts}

* - dimensional properties

\section{References}

[1] Cowin S.C. (1974): The theory of polar fluids. - Adv. Appl. Mech., vol.14, 279.

[2] Raptis A. (1982): Effects of couple stresses on the flow through a porous medium. - Rheol. Acta, vol.21, 736.

[3] Patil P.M. and Hiremath P.S. (1992): A note on the effects of couple stresses on the flow through a porous medium.Rheol. Actam., vol.31, 206.

[4] Patil P.M. and Hiremath P.S. (1993): Free convection effects on the oscillatory flow of a couple stress fluid through a porous medium. - Acta Mechanica, vol.98, 143.

[5] Sharma R.C. and Gupta M.A. (1995): Thermal convection in micropolar fluids in porous medium. - Int. J. Engrg. Sci., vol.33, 1887.

[6] Sharma R.C. and Kumar P. (1998): Effect of rotation on thermal convection in micropolar fluids in porous medium. - Indian J. Pure Appl. Math., vol.29, 95.

[7] Raptis and Takhar H.S. (1999): Polar fluid through a porous medium. - Acta Mechanica, vol.135, pp.91.

[8] Kim Y.J. (2001): Unsteady convection flow of micro polar fluids past a vertical porous plate embedded in a porous medium. - Acta Mechanica, vol.148, pp.105-116.

[9] Hassanien I.A., Essawy A.H. and Moursy N.M. (2004): Natural convection flow of micropolar fluid from a permeable uniform heat flux surface in porous medium. - Appl. Math. Comput., vol.152, 32.

[10] Sharma R.C. and Sharma M. (2004): On couple stress fluid permeated with suspended particles heated and soluted from below in porous medium. - Indian J. Phys. B, vol.78, 189.

[11] Helmy A.K. (1998): MHD unsteady free convection flow past a vertical porous plate. - J. ZAMM, vol.98, pp.255270.

[12] El-Hakiem M.A., Mohammadein A.A., El-Kabeir S.M.M. and Gorla R.S.R. (1999): Joule heating effects on magnetohydrodynamic free convection flow of a micropolar fluid. - J. Int. Comm. Heat Mass Tran., vol.26, No.2, pp.219-227

[13] Sharma R.C. and Thakur K.D. (2000): On couple stress fluid heated from below in porous medium in hydromagnetics. - Czech. J. Phys., vol.50, 753.

[14] Sharma V. and Sharma S. (2000): Thermosolutal convection of micropolar fluids in hydromagnetics in porous medium. - Indian J. Pure Appl. Math., vol.31, pp.13-53.

[15] El-Amin M.F. (2001): Magnetohydrodynamic free convection and mass transfer flow in micropolar fluid with constant suction. - J. Magn. Mater., vol.148, pp.105-116.

[16] Kim Y.J. (2001): Unsteady MHD convection flow of polar fluids past a vertical moving porous plate in porous medium. - Int. J. Heat Mass Transfer, vol.44, 2791. 
[17] Ibrahim F.S., Hassanien I.A. and Bakr A.A. (2004): Unsteady magnetohydrodynamic micropolar fluid flow and heat transfer over a vertical porous plate through a porous medium in the presence of thermal and mass diffusion with a constant heat source. - Can. J. Phys., vol.82, 775.

[18] Rahman M.M. and Sattar M.A. (2006): Magnetohydrodynamic convective flow of a micropolar fluid past a continuously moving porous plate in the presence of heat generation/absorption. - ASME J. Heat Transfer, vol.128, 14.

[19] Ahmed N., Kalita H. and Baruah D.P. (2010): Unsteady MHD free convective flow past a vertical porous plate immersed in a porous medium with Hall current, thermal diffusion and heat transfer. - International Journal of Engineering Science and Technology, vol.2, pp.59-74.

[20] Khandelal K., Gupta, Anil, Poonam and Jain N.C. (2003): Effects of couple stress on the flow through a porous medium with variable permeability in slip regime. - Ganita, vol.54, No.2, pp.203-212.

[21] Sharma P.K. and Chaudhary R.C. (2003): Effect of variable suction on transient free convective viscous incompressible flow past a vertical plate with periodic temperature variation in slip flow regime. - Emirates Journal of Engineering Research, vol.8, No.2, pp.33-38.

[22] Sharma P.K. (2005): Influence of periodic temperature and concentration on unsteady free convective viscous incompressible flow and heat transfer past a vertical plate in slip-flow regime. - Matematicas XIII (1), pp.51-62.

[23] Chaudhary R.C. and Jha A.K. (2008): Effects of chemical reactions on MHD micropolar fluid flow past a vertical plate in slip flow regime. - Appl. Math. Mech. -Engl. Ed., vol.29, No.9, pp.1179-1184.

[24] Mishra N.K., Sharma V.K. and Rajput D. (2011): Effect of mass transfer on the free convective flow through porous medium with variable permeability in slip flow regime with couple stress. - Am. J. Sc. Ind. Res., vol.2, No.3, pp.469-477.

[25] Oahimire J.I., Olajuwon B.I., Waheed M.A. and Abiala I.O. (2013): Analytical solution to MHD micropolar fluid flow past a vertical plate in a slip-flow regime in the presence of thermal diffusion and thermal radiation. - Journal of the Nigerian Mathematical Society, vol.32, pp.33-60.

Received: September 12, 2015

Revised: March 19, 2016

\section{Appendix}

$$
\begin{aligned}
& K_{1}=\frac{1}{1+\alpha}, \quad K_{2}=\frac{2 \alpha}{1+\alpha}, \quad K_{3}=\frac{N}{1+\alpha}, \quad K_{4}=n K_{1}-K_{3}, \\
& K_{5}=\frac{\operatorname{Pr}+\sqrt{\operatorname{Pr}^{2} 4 n \operatorname{Pr}}}{2}, \quad K_{6}=\frac{\beta+\sqrt{\beta^{2}-4 n \beta}}{2}, \\
& K_{7}=\frac{K_{1}+\sqrt{K_{1}^{2}+4 K_{3}}}{2}, \quad K_{8}=\frac{K_{2} \beta}{\beta^{2}-K_{1} \beta-k_{3}}, \\
& K_{9}=-\frac{K_{1} \mathrm{Gr}}{\operatorname{Pr}^{2}-K_{1} \operatorname{Pr}-k_{3}}, \quad K_{10}=\frac{K_{1}+\sqrt{K_{1}^{2}+4 K_{1} K_{4}}}{2}
\end{aligned}
$$




$$
\begin{aligned}
& K_{11}=\frac{K_{2} K_{6}}{K_{6}{ }^{2}-K_{1} K_{6}+K_{4}}, \quad K_{12}=\frac{A K_{2} \beta^{2}}{n\left(\beta^{2}-K_{1} \beta+K_{4}\right)}, \\
& K_{13}=\frac{A K_{1} K_{7}}{K_{7}^{2}-K_{1} K_{7}+K_{4}}, \quad K_{14}=\frac{A K_{1} K_{8} \beta}{\beta^{2}-K_{1} \beta+K_{4}}, \\
& K_{15}=\frac{A K_{1} K_{9} \operatorname{Pr}}{\operatorname{Pr}^{2}-K_{1} \operatorname{Pr}+K_{4}}, \quad K_{16}=\frac{A K_{l} \mathrm{Gr} \operatorname{Pr}}{n\left(K_{5}^{2}-K_{1} K_{5}+K_{4}\right)}, \quad K_{17}=\frac{A K_{l} \mathrm{Gr} \operatorname{Pr}}{n\left(\operatorname{Pr}^{2}-K_{1} P+K_{4}\right)}, \\
& K_{18}=K_{17}(1+h \operatorname{Pr})-1-K_{15}(1+h \operatorname{Pr})-K_{16}\left(1+h K_{5}\right)+ \\
& -C_{5}\left(K_{12}+K_{14}+h K_{12} \beta+h K_{14} \beta\right)-C_{7}(1+h) K_{13} \text {, } \\
& K_{19}=C_{5} \beta^{2}\left(K_{12}+K_{14}-\frac{A}{n}\right)+K_{7}^{2} K_{13} C_{7}+\operatorname{Pr}^{2} K_{15}+K_{5}^{2} K_{16}-\operatorname{Pr}^{2} K_{17}, \\
& C_{1}=0, \quad C_{2}=1, \quad C_{3}=-\frac{A}{n} \operatorname{Pr}, \quad C_{4}=0, \\
& C_{5}=\frac{\left[\operatorname{Pr}^{2} K_{9}\left(1+h K_{7}\right)-K_{9} K_{7}^{2}(1+h \operatorname{Pr})\right]}{\left[\beta^{2}\left(1-K_{8}\right)+K 7 h \beta^{2}(1-K 8)+K_{7}^{2} K_{8}(1+h \beta)\right]}, \\
& C_{6}=\frac{\left[K_{10}{ }^{2} K_{18}+K_{19}+h K_{19} K_{10}\right]}{\left[K_{6}-K_{6}{ }^{2} K_{11}+h K_{10} K_{6}-h K_{10} K_{6}^{2} K_{11}+h K_{6} K_{11} K_{10}{ }^{2}+K_{11} K_{10}{ }^{2}\right]}, \\
& C_{7}=\frac{C_{5} \beta\left(1-K_{8} \beta\right)-\operatorname{Pr}^{2} K_{9}}{K_{7}^{2}}, \quad C_{8}=\frac{C_{6} K_{6}\left(1-K_{6} K_{11}\right)-K_{19}}{K_{10}^{2}} .
\end{aligned}
$$

